\title{
ESCRITURA Y CONQUISTA: FRAGMENTOS PARA UNA HISTORIA DEL ESPAÑOL AMERICANO
}

\author{
Carlos Garatea Grau \\ Pontificia Universidad Católica del Perú
}

\section{RESUMEN}

En este breve trabajo se ofrece un conjunto de reflexiones sobre la importancia de la historia de la escritura en América, en especial, sobre la historia de la escritura en comunidades fundamentalmente orales, como la andina. Con este propósito, el análisis se concentra en las notas y apuntes que, sobre el particular, hicieron el Inca Garcilaso, en sus Comentarios reales (1609) y Guamán Poma de Ayala, en su Primer nueva Crónica y Buen Gobierno (1615). Aunque se trata de una primera aproximación al tema, el ensayo muestra el impacto social y cultural ocasionado por la imposición de un nuevo medio de comunicación en el mundo andino.

Palabras ClaVE: Español de América, historia de la escritura, Inca Garcilaso, Guamán Poma de Ayala, contacto de lenguas.

\section{ABSTRACT}

This brief work offers a set of reflections on the importance of the history of writing in America, especially on the history of writing in fundamentally oral communities, such as the Andean. To this end, the present analysis focuses on notes and comments written on this particular aspect by the Inca Garcilaso in Comentarios reales (1609) and Guaman Poma de Ayala in his Primera nueva Crónica $y$ Buen Gobierno (1615). Although this is a first approximation to the subject, this essay shows the social and cultural impact caused by the imposition of a new means of communication in the Andean world.

KEYWORDS: Spanish of America, history of writing, Inca Garcilaso, Guamán Poma de Ayala, language contact. 
El mejor homenaje que puede ofrecerse a un amigo es conservarlo en la memoria, hablar sobre él, citarlo y, en lo posible, invitar a quienes no lo conocieron a que se acerquen a sus trabajos, sus textos, aunque discrepen de sus ideas, o sencillamente a que aprecien con gratitud lo que, sin saberlo, nos dejó. Cuando el olvido se impone, lo perdemos. Y no hay vuelta atrás. Aprecié y respeté mucho a Jesús Bustos Tovar. En reconocimiento a sus cualidades, personales e intelectuales, y a su amistad, quiero recuperar un breve pasaje del trabajo que publicó el año 2000 con el título «Texto, discurso e historia de la lengua». Pienso que esas líneas expresan la orientación que mantuvo en su vida académica y que no se cansó de señalar como la vía que asegura un trabajo filológico de calidad, integral, propio de las ciencias humanas y de los interesados en la historia del español. Aunque el tiempo transcurrido desde que apareció el texto puede dar la impresión de que el pasaje contiene ideas aceptadas por muchos investigadores -ahora esperables en manuales e introducciones- en su momento, a mi juicio, resumió la defensa de la filología que emprendió Jesús ante quienes promovían concepciones y metodologías teñidas de especulación, adversas a la dimensión histórica de la lengua y a entender todo texto como acto comunicativo. Bustos razonó lo siguiente:

[...] hoy se impone un enfoque pluriangular que asedie al texto de tal modo que provoque la aparición de algunas luces ocultas, precisamente porque se ha olvidado que un texto (literario o no literario, tanto da) es ante todo un acto de comunicación que resulta de una intención comunicativa primaria, organizada por medio de un proceso discursivo [...] el filólogo no puede quedarse en el papel de mero restaurador de la letra de los textos (fase evidentemente indispensable y primaria), sino que debe interpretar el sentido de los textos y dar cuenta de los mecanismos de organización textual [...] El punto de partida será siempre la literalidad del enunciado (base de toda restauración filológica), pero si el fin último del análisis textual es interpretar los textos, hará falta incorporar los criterios que permitan pasar del significado al sentido. Muchas veces bastará con tener en cuenta los factores pragmáticos, pero en muchas otras ocasiones será preciso aplicar nuestro conocimiento de la historia cultural para inferir los valores textuales que afectan el sentido global del texto (Bustos 2000: 70 y 92).

En lo que sigue pretendo explorar algunas de estas ideas. En particular, quiero concentrarme en el lazo del texto con el sentido y la historia cultural. Lo haré alejándome de los tipos textuales que habitualmente captaron el interés y la vocación filológica de Bustos Tovar y, más bien, me acercaré a dos obras fundamentales en el estudio del español americano, sobre todo del peruano: una de ellas, la primera, fue elaborada en España y gozó de rápida aceptación y de singular difusión entre los lectores del siglo XVII, 
mientras que la otra, la segunda, fue escrita en los Andes y estuvo «perdida» cerca de tres siglos. Me refiero a los Comentarios reales del Inca Garcilaso de la Vega (1609) y a la Primera corónica y buen gobierno de Guamán Poma de Ayala (1615). No creo necesario insistir en el valor historiográfico y lingüístico de ambas obras ni en que una y otra responden a situaciones y propósitos distintos, no obstante que los autores coinciden en el interés por «mostrar»y «documentar» diferentes momentos de la historia del Perú y de ofrecer una historia «verdadera», en virtud de su origen andino y de su condición quechuahablante, sobre todo el Inca, mientras que el cronista se apoya en el conocimiento de su entorno. Hay abundante bibliografía en este y en muchos otros sentidos sobre los dos libros ${ }^{1}$. Lo que me interesa aquí es resaltar las reflexiones y expectativas que exponen los autores sobre la escritura, medio y sistema de comunicación impuesto en una sociedad circunscrita a la oralidad, en lengua quechua. Los fragmentos que mostraré ofrecen información que, sin duda, colabora con el sentido general de las obras y permiten recuperar otra vertiente -o tal vez sea la misma vertiente pero vista desde otro ángulo- de la historia del español de América, sobre todo de la imposición del español en comunidades que tuvieron (en realidad, que tienen) no solo otras lenguas, sino otras maneras de conservar la memoria histórica, otras maneras de referir a sus dioses y de proyectarse a un futuro que cambió, violenta y definitivamente, con la llegada del español y con las nuevas modalidades de concebir y regular las relaciones sociales que trajo la lengua europea a los Andes, de la mano de un Estado y una Iglesia que impusieron normas y modelos de conducta capaces de decidir la supervivencia de la población indígena. En este contexto, ambos autores realizan algunas reflexiones, a veces simples apuntes al pasar, sobre la escritura, vale decir, sobre el discurso escrito en español, y razonan, con distinta profundidad, sobre su impacto y trascendencia en el mundo colonial, cuando, en paralelo, los efectos del contacto iban consolidando una nueva variedad del español en la oralidad ${ }^{2}$.

\footnotetext{
${ }^{1}$ En otros trabajos he razonado sobre el alcance de las dos obras, en particular, en torno a su utilidad para conocer registros distintos del español colonial y la manera en que se reflejan los efectos del contacto del español con las lenguas andinas. Cf. Garatea (2010, 2013, 2015a y 2017). Como digo arriba, la bibliografía es amplísima. Me limito, por ello, a citar los estudios que a mi juicio contribuyen directamente con la línea argumental que planteo aquí; asumo todas las omisiones y las imprecisiones que seguramente encontrará el lector.

2 Pongo por delante una advertencia: solo me referiré a un puñado de citas. No pretendo, por tanto, agotar el tema ni abarcar la totalidad de reflexiones anotadas por los dos autores. Sirva, al menos, este puñado como aliciente para un trabajo en proceso y para mostrar un campo de investigación relativamente denso. Véase por cierto Cárdenas (1997 y 2001); Cerrón (2013); Durston (2007); Godenzzi y Garatea (2017); Rivarola (2003); Quispe (2006).
} 


\section{LA LLEGADA DE LA ESCRITURA}

Las reflexiones anteriores vienen a cuento porque la implantación del español en América no fue un proceso limitado a su difusión oral. Muchas veces se olvida que, con la oralidad, llegaron al continente la escritura y una variedad de modelos textuales asegurados secularmente en la memoria, en la vida social y en la concepción del mundo de quienes cruzaron el mar en búsqueda de fortuna y prestigio. Aunque su dominio fuera desigual y aunque sea cierto que muchos analfabetos llegaron a distintos puntos del continente $^{3}$, en diferentes momentos, la escritura -tal vez sea mejor decir el discurso escrito- gozó de prestigio entre los conquistadores y fue medio privilegiado en la idea de estado, de poder político y de fe que impusieron a las poblaciones amerindias. Basta pensar en el Requerimiento y en la «puesta en escena» que suponía su lectura y posterior ejecución en la conquista del territorio para admitir que la escritura estuvo presente desde que ponen el pie en tierra firme; otro ejemplo del protagonismo que ocupan los textos -en este caso, la Biblia- es el relato del encuentro de Cajamarca entre Pizarro y Atahualpa ${ }^{4}$, pero se hace evidente cuando se recuerda la inconmensurable variedad de documentos dirigidos desde la Corte a sus dominios americanos y viceversa, conservados en archivos españoles y americanos. Por si fuera poco, no hay que olvidar que la enseñanza de la lectura y de la escritura es una constante en la política lingüística impulsada por la Corona en sus colonias americanas ${ }^{5}$, cuyos efectos en la conciencia lingüística de los bilingües no son suficientemente conocidos ni suelen merecer mayor atención, no obstante que existe consenso sobre su relevancia en la historia de Hispanoamérica, en especial para entender cómo se difundieron los modelos y las tradiciones textuales que vemos aparecer en documentos escritos por indígenas con diverso grado de competencia bilingüe y sin que su aprendizaje pueda atribuirse a una pasajera estancia escolar ni al contacto espontáneo. No creo, pues, que sea exagerado afirmar que, en un extremo, la conquista y la colonización de América fueron una conquista y una colonización textual (Garatea 2005): fue el discurso escrito el que

${ }^{3}$ Hoy sabemos, por cierto, que la imagen de un asalto en manos de gente sin preparación debe ser matizada. El asalto se dio, claro está, pero en él intervino un nutrido grupo de gente letrada, educada, «culta» y muy creyente. Lo expuso ya Rosenblat (1967/2017).

${ }^{4}$ Oesterreicher (1997) ofrece un valioso e interesante análisis del «Requerimiento», cuyas implicancias pragmáticas y discursivas, aplicadas al encuentro de Cajamarca, integran un conjunto de fenómenos comunicativos y sociales que acompañaron la conquista de América y la implantación del español en suelo inca.

5 Fuentes documentales insustituibles son, a mi juicio, Konetzke (1953 y 1984); también Solano (1992). Para la política colonial, en cuanto a su impacto en el Perú, remito a Mannheim (1989) y Durston $(2007,2008)$; complementa bien este panorama la reciente edición de Godenzzi y Garatea (2017) sobre la historia de la literatura durante los primeros años de la Colonia. 
articuló el sistema político, social y cultural impuesto y con el que se estableció una desigual manera de vincularse con los pueblos amerindios, mientras que en la vida diaria, en el trato y en el contacto del día a día, no siempre homogéneo ni simultáneo, se labraba, a pasos y ritmos difíciles de precisar, el surgimiento de nuevas variedades de español ${ }^{6}$ y la aparición de entornos comunicativos sujetos a necesidades y condiciones que propiciarían matices innovadores en la lengua española.

Pues bien, lo habitual es que el énfasis caiga en la oralidad; mejor dicho, y para ser más preciso, lo habitual es que el énfasis caiga en inferencias a partir de huellas textuales o, si se quiere, gráficas, que podrían deberse a fenómenos concurrentes en el habla. Aunque en esta afirmación hay mucha tela que cortar y expuesto de esa manera peca de general, lo cierto es que, grosso modo, es la perspectiva privilegiada en la historia del español americano $^{7}$. Todavía no se ha valorado la historia de la escritura en América ni la difusión de modelos textuales ni la suerte de la enseñanza de la escritura a la población indígena; menos atención ha recibido la influencia de la escritura en la percepción del contexto sociolingüístico que empezó a gestarse de la mano de una lengua y de un uso particular, el español escrito, ajeno a la mayoría de la población pero que súbitamente pasó a imponerse en ella y a sobreponerse a las demás manifestaciones lingüísticas. El discurso escrito ocupó rápidamente la cúspide de la diglosia; en el otro polo, el inferior, estuvo el quechua. Quedó, por cierto, una franja intermedia en la que debió decantarse el contacto, en diversas intensidades, con efectos distintos y con grados igualmente variables, en función de consideraciones sociales y políticas o de las oportunidades de castellanización que surgieron en el interior del mundo colonial. Sin duda que algún tipo de presión debió ejercer el prestigio del discurso escrito, en cualquiera de sus modalidades, sobre el uso oral del español, una lengua que acusaba los efectos del contacto, sea instaurando patrones ideales de «corrección y cultura», a los que los hablantes aspiraban llegar, en determinados contextos, sobre todo de distancia comunicativa, o haciendo retroceder las innovacio-

${ }^{6}$ A pesar de la imprecisión que ocasiona una generalización de este tipo, remito a Cerrón Palomino (2003), Rivarola (1990 y 2001) para ponderar el sentido de «nueva variedad de español». Resumo la discusión en Garatea (2010 y 2017).

${ }^{7}$ Subrayo la preferencia porque no tengo espacio para argumentar en esa línea. Me limito, por ello, a decir aquí que se trata de la perspectiva que, con toda justicia, tuvo especial impulso desde la segunda mitad del siglo xx, cuando la lingüística -mejor dicho, algunos investigadores- se encargaron de negar el valor de los textos, del discurso escrito, de la literatura, como dimensiones y prácticas atendibles e importantes en el conocimiento del funcionamiento de una lengua. La lengua oral ocupó el centro y la escritura fue separada y postergada. En este marco, tienen particular relevancia las ideas de Narbona (2008 y 2015) porque rescata, con agudeza, la función documental que tienen los textos literarios cuando son leídos (no vistos) con criterio filológico. 
nes, surgidas o no del contacto, que lograban ganar espacio en el habla. De manera que el discurso escrito contribuyó a instaurar una escala valorativa ${ }^{8}$, valoraciones que, sin duda, influyeron en la percepción de los aprendices de español o de quienes lograban algún grado de bilingüismo y algún dominio en la producción de textos escritos en español. Creo que, por esta vía, la escritura fue instaurando una idea de «lengua culta», de «estándar» y de «criterios de corrección idiomática» en el imaginario colectivo que ha logrado sobrevivir al paso del tiempo y regir, hasta hoy, la actuación verbal de millones de hispanoamericanos, sean o no bilingües.

Ciertamente que la irrupción del español en suelo americano ofreció la oportunidad para que las lenguas indígenas sean usadas en el nivel de la escritura, oportunidad aprovechada, sin embargo, solo parcialmente durante el período colonial, pues no hubo un desarrollo consistente en ese sentido (Garatea 2005 y 2010). La experiencia en México, por ejemplo, donde se tuvo al famoso colegio Santa Cruz de Tlatelolco, bajo la dirección del franciscano Bernardino Sahagún, dedicado, entre otras cosas, a la formación de escribientes en su lengua indígena, contrasta radicalmente con lo sucedido en el Perú, donde no hubo nada parecido, salvo iniciativas aisladas de algunos religiosos, como la del P. Bertonio, con un grupo aimara (Cerrón Palomino 2003: 147), o de otros tantos cuyos nombres ignoramos hasta hoy pero cuya existencia no podemos negar. La investigación reciente está encendiendo nuevas luces sobre este punto y ya empieza a vislumbrarse un horizonte que parece anunciar que un contingente de indígenas más nutrido del que se creía tuvo acceso a algún tipo de formación en escritura y lectura en español (Rivarola 2000 y 2009). Esas noticias, aunque pocas y limitadas, son valiosas e iluminadoras del trasfondo del contacto de lenguas y de la compleja red de vínculos que se instauró entre los grupos sociales y étnicos durante la colonia y que configuran un contexto que no se reduce a dos grupos opuestos sino que posee zonas intermedias, fronteras, espacios comunicativos, donde el contacto tuvo particular intensidad y donde la castellanización parece haberse dado por razones imposibles de homologar. A ese grupo, creo, pertenece Guamán Poma de Ayala, por ejemplo ${ }^{9}$. En cualquier caso, es perfectamente probable que los individuos que, por posición social o por simple oportunidad, tuvieron mayor contacto con diversos registros diafásicos o con diversos tipos de textos, hicieran un trasvase de formas y modos de enunciación del discurso escrito a sus prácticas orales. Y si, además, ellos gozaron de algún reconocimiento en el entorno, sus

\footnotetext{
${ }^{8}$ Lo dicho debió suceder entre el medio gráfico y el fónico y sus respectivas realizaciones de inmediatez y distancia comunicativas, para decirlo acogiendo la terminología difundida por Koch y Oesterreicher en muchos trabajos. Remito solo a su libro del 2007.

${ }^{9}$ Para todos los efectos me atengo a Adorno (1989 y 1991).
} 
expresiones pudieron propagarse entre quienes no tenían acceso directo a la tradición y a la cultura escritas. Pero hay que ir con calma en esta ruta. Aún es poco lo que se tiene. Por lo pronto, en el Perú, como en otras regiones, la norma fue adecuar la representación gráfica de contenidos y formas gramaticales, propios de las lenguas indígenas, a patrones exigidos por el español escrito (Rivarola 2002; Durston 2003 y 2008). El paso de la voz a la letra fue generalmente obra de escribanos y religiosos que actuaban según las exigencias impuestas por el sistema colonial y elaboraban sus textos de acuerdo con la función y los propósitos estipulados para cada uno de ellos. Otras veces fueron indios, con un bilingüismo no siempre coordinado, quienes, en virtud de su privilegiada posición, como curacas o indios principales, hicieron uso del discurso escrito en español, dejando preciosas huellas de su oralidad en él, a pesar de sus esfuerzos por encauzar sus textos de acuerdo con las exigencias de las tradiciones textuales recibidas y requeridas en el contexto comunicativo inmediato (Garatea 2017).

\section{El InCA GARCILASO y la ESCRItURA}

El Inca Garcilaso no necesita presentación. La bibliografía en torno a su obra y a su vida es profusa y tan heterogénea y copiosa que es difícil encontrar un tema que no haya merecido la atención de los especialistas. Hay, pues, de todo y se ha dicho prácticamente todo. Sin embargo, en los Comentarios reales (1609) es posible encontrar algunas vetas que merecen ser exploradas un poco más; sucede lo mismo con su vida y, en particular, con su formación intelectual y con la manera en que usó y, muchas veces, refundió sus fuentes en un discurso historiográfico coherente y lúcido (cf. Rodríguez 1993). Lo que, en cambio, genera admiración y rápido consenso es el dominio del español que ofrece su obra, una prosa, un ritmo y una sintaxis que lo pusieron a la altura de los mejores exponentes del Siglo de Oro y que le valieron ser incluido entre los autores que inauguran el primer tomo del Diccionario de Autoridades en 1726. Pocas veces recordamos que el Inca Garcilaso es una de las autoridades del español. La Academia reconoció el valor y el dominio estilístico que logra el Inca en su segunda lengua, si nos atenemos a que su lengua materna es el quechua. Dicho de otro modo: la Academia lo distingue por la lengua del padre y no por la lengua adquirida en la leche materna, para decirlo con la expresión usada por el autor cuando señala (y reitera) ser hablante de quechua y cuyo alcance, en Los Comentarios, no se agota en remitir a la primera lengua, ni a la extensión semántica que la reviste de un ideal de pureza y corrección, sino que, junto a ello, la expresión es anclada por el Inca para referir a la lengua o a la variedad hablada en un lugar determinado: el Cuzco, la capital del Imperio, 
cuna de Garcilaso ${ }^{10}$. En distintos pasajes insiste en su condición de indio quechua mediante afirmaciones como: «He procurado traducir fielmente de mi lengua materna, que es la del Inca, en la ajena, que es la castellana» (I, 17); o mediante la referencia al Cuzco y la variedad de quechua hablado allí: «cuánto se engañan en declarar el lenguaje del Perú los que no la mamaron en la leche de la misma ciudad del Cozco, aunque sean indios, porque los no naturales della, también son extranjeros y bárbaros en la lengua, como los castellanos» (V, 21). Pero, de la lectura de los Comentarios y de las noticias que hoy conocemos sobre su vida y formación, no parece haber razones para oponer el quechua y el español como hace el Inca; ciertamente no en cuanto a su dominio de español ni en cuanto a su competencia idiomática. Ya Rivarola (2001) indicó que, con el mismo derecho que reclama su sangre india y el quechua como lengua materna, pudo reclamar su otra mitad, la española. El español es la lengua que hereda del padre, la que usa cuando escribe, en la que lee y estudia, la que lo lleva a la fama (Garatea 2015a y b). Y, por otra parte, no es difícil asumir que fue durante sus años de formación en España cuando asimiló el valor retórico que tiene el símil de la lengua familiar con la leche materna, una analogía cimentada durante el desarrollo de las reflexiones sobre la lengua, como imagen que permitía distinguir la adquisición de la lengua familiar, la del entorno inmediato, de cualquier otra ajena a las primeras experiencias de hablante ${ }^{11}$. El Inca emplea la figura aplicándola a la lengua andina que mejor conoce, la lengua del círculo materno, la que hablan sus parientes, quienes conservan la memoria histórica y le ceden al autor el recuerdo de bienes y hechos perdidos con la imposición del nuevo régimen político y religioso. Afirmada narrativamente su condición quechuahablante, Garcilaso convierte su lengua materna en el medio que le permite elaborar una historia «verdadera», propia, una historia transmitida de boca en boca, en el seno de la vida familiar y en el ámbito de la comunidad que lo vio nacer y a la cual se debe. Para el Inca, la lengua es el medio que le permite una adecuada y veraz interpretación de los hechos, de las historias y de las cosas que llenaron el espacio y dieron sentido a la vida del hombre andino durante el Imperio Inca. Todo ese mundo es un mundo quechua. Y en ese punto es cuando sus reflexiones sobre la escritura adquieren sentido. Solo

${ }^{10}$ De las ideas arriba mencionadas y su despliegue en el discurso del Inca se han ocupado Rivarola (2001 y 2003); Cerrón Palomino (2013); con otros elementos Garatea (2019). Por cierto, la analogía con Roma y el latín es explícita.

${ }^{11}$ A ello alude, por ejemplo, Juan de Valdés en su Diálogo de la lengua (1533/1989: 5), cuando, en el marco de la questione de la lingua y de Pietro Bembo, razona en estos términos: «todos los hombres somos más obligados a ilustrar y enriquecer la lengua que nos es natural y que mamamos en las tetas de nuestras madres, que no la que nos es pegadiza y que aprendemos en libros». 
él, quechuahablante, es capaz de escribir aquello que persiste en la tradición oral. Y a cumplir con ese fin se aboca en Los Comentarios. En ocasiones celebra las virtudes de la escritura; en otras lamenta las limitaciones de las tradiciones orales; pero, en ningún caso, la ausencia de escritura es motivo de remilgo ni de amargura.

Como decía, el Inca no miente, ni inventa, deja testimonio y elabora una historia con lo que conserva la tradición oral y que adquirió en «las mantillas» $(\mathrm{V}, 18)$ :

(Los incas) porque no tuvieron letras no dejaron memoria de sus grandes hazañas y agudas sentencias; y así perecieron ellas y ellos juntamente con su república. Sólo quedaron algunos de sus hechos y dichos encomendados a una tradición flaca y miserable enseñanza de palabra de padres a hijos la cual también se ha perdido con la entrada de la nueva gente y trueque de señorío y gobierno ajeno, como suele acaecer siempre que se pierden y truecan los imperios (VII, 8)

«Tradición flaca y miserable», dice el Inca, pensando en ese mundo que se perdió sin dejar huella. No parece, sin embargo, que sus antepasados ignorasen el valor de la memoria. A decir del Inca, hubo quienes tuvieron la función de preservar los hechos más relevantes, ponerlos a salvaguarda del tiempo y del olvido, aunque deba admitir que no alcanzaron la consistencia del discurso escrito y muchos hechos, hazañas y aventuras dignas de recordación se perdieron para siempre. Garcilaso hace una larga descripción que vale la pena citar y leer completa, en torno a las modalidades que cultivaron sus paisanos, con el deseo de preservar la historia de su pueblo. La preocupación de llevar la contabilidad (los quipus) anduvo limitada a los famosos nudos, aunque sugiere que tuvieron alguna utilidad adicional, que merecería otra discusión. Particularmente interesante es, por ejemplo, la función atribuida a los Amautas, creadores de textos breves, de fácil aprendizaje, cuyos contenidos dependían de hechos relevantes, próximos y situados, transmitidos de boca en boca entre jóvenes, en el campo, una suerte de canciones tradicionales. A pesar de ello -digo-, a pesar de las cualidades y del valor cultural y social que el Inca reconoce a esas alternativas mnemotécnicas, no deja de contraponerlas a las virtudes del discurso escrito y, en ello, en la comparación, la escritura gana. Escribe Garcilaso:

Las cuales pláticas tomaban los Indios Quipucamayoc de memoria, en forma de breves palabras y las encomendaban a la memoria, y por tradición las enseñaban a los sucesores de padres a hijos y descendientes, principal y particularmente en los pueblos o provincia donde había pasado y allí se conservaban más que en otra parte porque los naturales se preciasen de ellas. También usaban de otro remedio para que sus hazañas y las embajadas que traían al Inca y las respuestas que el inca daba se conservasen en la 
memoria de las gentes, y es que los Amautas, que eran los philosophos y sabios tenían cuidado de ponerlas en prosa en cuentos historiales breves, como fábulas, para que por sus edades los contasen a los niños y a los mozos y a la gente rústica del campo para que pasando de mano en mano y de edad en edad se conservasen en la memoria de todos. También ponían los historias en modo fabuloso con su alegoría [...]. Así mismo los Haravicus que eran los poetas componían versos breves y compendiosos, en los cuales encerraban la historia o la embajada o la respuesta del Rey, en suma decían en los versos todo lo que no podían poner en los nudos, y aquellos versos cantaban en sus triumphos y en sus fiestas mayores y los recitaban los incas noveles, cuando los armaban caballeros y desta manera guardaban la memoria de sus historias. Empero como la experiencia lo muestra, todos eran remedios perecederos, porque las letras son las que perpetúan los hechos, mas como aquellos Incas no las alcanzaron valiéronse de lo que pudieron inventar, y como si los nudos fueran letras, eligieron historiadores y contadores que llamaron Quipucamayu, que es el que tiene cargo de los nudos, para que por ellos y por los hilos y por los colores de los hilos, y con el favor de los cuentos y de la poesía, escribiesen y retuviesen la tradición de sus hechos: esta fue la manera de escribir, que los incas tuvieron en su república (VI, 9)

Pero si esa «fue la manera de escribir que los incas tuvieron», no parece haber sido el Inca condescendiente ni indiferente ante la falta de un medio que les permita recuperar los hechos, traerlos al presente, contarlos y, por qué no, vivirlos otra vez. Durante el supuesto diálogo con un tío suyo, Garcilaso, con cierto reproche, algo inusual en alguien cuya prosa es extremadamente cuidada y regular, cuenta haber platicado lo siguiente:

Inca, tio, pues no ay escritura entre vosotros, que es la que guarda la memoria de las cosas pasadas, que noticias teneys del origen y principio de nuestros Reyes? Porque alla los españoles y las otras naciones sus comarcanas, como tienen historias divinas y humanas, saben por ellas cuando empeçaron a reynar sus Reyes. [...] Empero vosotros que careceys dellos, que memoria teneys de vuestras antiguallas. [...] Sobrino, yo te las diré de muy buena gana, a ti te conviene oyrlas y guardarlas en el coraçon (es frasis dellos por decir en la memoria) ... (I, 15).

Aunque se trata de un diálogo imaginado, no deja de tener interés el «reclamo» y la sorpresa que transmite la interpelación al tío. La demanda al tío por la falta de escritura es el reclamo por la ausencia de un medio que el Inca sabe europeo. Bien podría resumirse la cuestión en una pregunta absurda: ¿Por qué no tienen lo que no pueden tener? Sin duda que es un recurso retórico, utilísimo para el lugar que asume el autor como narrador de una historia a la que tiene acceso gracias a su lengua materna, con la que se comunica con el tío, por cierto. Dicho de otra manera, lo que deja en claro es que, como no tuvieron escritura, toda la historia es una 
historia oral y quechua. Él sabe quechua. Ergo: él cuenta la verdad ${ }^{12}$. Pero se cuida de que ello no perjudique la grandeza cultural que le interesa afirmar en la historia del Imperio Inca y en el lector de su obra, un lector europeo acostumbrado a referentes, signos y estructuras que Garcilaso emplea para describir el mundo andino a individuos que solo podían acceder a él mediante la lectura, la imaginación y la fantasía. La ausencia de escritura podía ser tomada como señal de inferioridad. Su estrategia aquí busca desvirtuar el supuesto de que todo discurso escrito es verdadero, o, si se quiere, «más verdadero» que el oral, propenso a la fantasía, la fábula, rasgos que evidentemente socavan las pretensiones del historiador. Razona sobre este asunto a propósito del origen del Cuzco:

no hay que espantarnos de que gente que no tuvo letras, con que conservar la memoria de sus antiguallas, trate de aquellos principios tan confusamente, pues los de la gentilidad del mundo viejo con tener letras, y ser tan curiosos en ellas, inventaron fabulas tan dignas de risa, y mas que estotras, pues una dellas es la de Pirra y Deucalion, y otras que pudieramos traer a cuento: y tambien se pueden cotejar las de una gentilidad con las de otra, que en muchos pedazos se remedan; y así mismo tienen algo semejante a la historia de Noe... (I, 18).

Si bien el Inca es consciente de la importancia cultural e histórica de la escritura, sitúa su labor historiográfica en el contexto de una sociedad (la suya, por cierto) oral y en una lengua distinta del español, el quechua (también la suya). A ese mundo suyo no llega la lengua española, ni el común de los historiadores, pero es en esta lengua, el español, en que el mundo andino emerge ante los ojos del lector gracias a la habilidad, la cultura y la destreza bilingüe del Inca Garcilaso.

\section{Guamán Poma de Ayala y la voluntad de APrender a ESCRIbir}

La Nueva Crónica y Buen Gobierno de 1615 tuvo menos suerte que los Comentarios Reales de 1609, anduvo perdida durante siglos, expuesta a los

\footnotetext{
${ }^{12}$ A modo de ejemplo ofrezco tres citas en las que me parece confirmar lo dicho arriba: «Aunque ha habido españoles curiosos que han escrito las repúblicas del nuevo mundo, como la de México y la del Perú, y la de otros reinos de aquella gentilidad, no ha sido con la relación entera que de ellos se pudiera dar. Que lo he notado particularmente en las cosas que del Perú he visto escritas, de las cuales como natural de la ciudad del Cuzco, (que fue otra Roma en aquel imperio), tengo más larga y clara noticia que la que hasta ahora los escritores han dado [...] mi intención no es contradecirles, sino servirles de comento y glosa, y de intérprete en muchos vocablos indios que como extranjeros en aquella lengua interpretaron fuera de la propiedad de ella» [Proemio]; «... gallina para decir cobarde es hurto del lenguaje español, que en el de los indios no lo hay, y yo como indio doy fe desto» (IX, 23); «No sin causa escrivieron los historiadores lo que dizen y yo escrivo lo que fue» (II, 26).
} 
avatares del comercio y de la ambición, hasta que terminó en la Biblioteca Real de Dinamarca, donde está actualmente ${ }^{13}$. Probablemente se deba a ello que, aunque reconocida y aplaudida por especialistas, todavía no alcance el prestigio mundial que tiene el Inca. Por cierto, la Corónica es más exigente con el lector que los Comentarios. Está compuesta de 1180 páginas y 400 ilustraciones que acompañan pasajes, descripciones y escenas. El texto es una larga carta dirigida al rey Felipe III con el propósito de informarle de los atropellos e injusticias que padece la población indígena por la administración colonial (Adorno 1989 y 1991); Guamán Poma no solo se presenta como autor, el responsable de la historia, en ocasiones dirigiéndose al lector, interpelándolo, o afianzando la tensión narrativa ${ }^{14}$, sino que, en paralelo, apoya la veracidad de su historia en su calidad -digamos- de testigo. Mientras Garcilaso recurre al quechua y a lo que le contaron, Guamán Poma se apoya en lo que ve y oye, un testigo de vista, para decirlo a la usanza jurídica. Y lo hace componiendo una obra -la llama carta- que incluye una rica y bien distribuida tipología textual: hay prólogos, descripciones, diálogos, leyes, memoriales, testamentos, etc., y dibujos, muchos dibujos con leyendas y anotaciones. La obra es una obra compleja, un armazón compuesto de muchos tipos de piezas, articuladas (Garatea 2018). Nada de eso sucede en Garcilaso: más lineal, homogéneo y, si se me permite, regular. Con Guamán Poma, los cambios estilísticos abundan en el texto, sin que ponga en riesgo la estructura general de la obra ni se pierda el hilo del discurso. Si en Garcilaso la prosa engalana la plaqueta del Siglo de Oro, con Guamán Poma sucede algo distinto, por original y extraño a los cánones literarios: conviven niveles distintos de español y dos lenguas. Digamos que contiene un español culto, estándar, semejante al de Garcilaso, habitual en cualquier lugar de habla española; en algunos pasajes el estilo es el de una prosa cuidada y fina o está inscrita en tradiciones discursivas y formulismos propios de textos jurídicos y religiosos; hay, por cierto, otro español claramente interferido por el quechua, la lengua materna del autor, a veces difícil de comprender por los quiebres morfosintácticos y semánticos, y, al mismo tiempo, en ocasiones, aunque la prosa acusa la presión quechua, no se oscurece el contenido, se entiende y, de esta manera, en esos grados de interferencia, el lector encuentra el despliegue de lo que parece ser efecto del contacto de lenguas, una presión que, como se sabe, dio pie

13 Para el periplo del texto remito a Adorno (1980 y 1991).

${ }^{14}$ Como ejemplo cito algunos fragmentos dirigidos al lector: «Aués de uer, cristiano letor, que por amor de Dios hazed otro tanto bosotros» (819/833); «Escriuir es nunca acauar. Y ací en común escribo para el buen exemplo. Ya los letores sabrán y apurarán de sauer que la culpa es de sus perlados» (644/658); «El autor don Felipe Guaman Poma de Ayala, digo que el cristiano letor estará marauillado y espantado de leer este libro y corónica y capítulos y dirán que quién me la enseñó, que como la puede sauer tanto» $(701 / 715)$. 
al surgimiento de la variedad andina del español; hay un tercer peldaño que corresponde al quechua, muchas veces escrito como traducción, otras como citas o precisiones en torno a referentes o voces andinos; valgan verdades, incluso cuando no es explícito, el quechua está presente en la crónica (Garatea 2017 y 2018). Guamán Poma impregna toda la crónica del contexto quechua. También lo español está en un entorno quechua. El lector lo percibe de principio a fin. Esta convivencia lingüística da a la obra un valor singular para el estudio del español americano y, en particular, del peruano. Los tres registros de lengua conviven en el texto, y ocupan, a mi juicio, espacios y momentos en los que resultan pertinentes para ejemplificar o realzar algún contenido; ofrecen trazos y episodios de la compleja y poco conocida historia del español en este lado de América. Quiero decir con esto que su reflejo en el texto no es fruto del azar sino resultado de una conciencia lingüística que sabe cuándo y cómo decir cada cosa y qué modalidad emplear, lo que, sin duda, hace de Guamán Poma un autor excepcional. Si Garcilaso muestra un lado de la historia del español, el culto y «estándar», Guamán Poma muestra otro extremo, el de la variación, el contacto y la diversidad ${ }^{15}$. Guamán dice en tono de confidente:

Escogí la lengua e fracis castellana, aymara, colla, puquina conde, yunga, quichiua ynga, uanca, chinchaysuyo, yauyo, andesuyo, condesuyo, collasuyo, cañari, cayanpi, quito. Pasé trauajo para sacar con el deseo de presentar a vuestra Magestad este dicho libro yntitulado Primer nueua corónica de las Yndias del Pirú y prouechoso a los dichos fieles cristianos, escrito y debojado de mi mano y engenio para que la uaridad de ellas y de las pinturas y la enbinción y dibuxo a que vuestra Magestad es enclinado haga fázil aquel peso y molestia de una letura falta de enbinción y de aquel ornamento y polido ystilo ${ }^{16}$ que en los grandes engeniosos se hallan $(10 / 10)$

De ese contexto multilingüe extrae lo que luego escribe en su crónica. Y, claro, en ese tránsito de una lengua a otra, de una tradición oral a un discurso escrito en otra lengua, Guamán Poma, como Garcilaso, define las

${ }^{15}$ Quiero decir con esto: los dos representan variedades distintas pero restringidas a tipos de discurso y a pequeños grupos sociales, tanto si vemos al Inca en el marco de la sociedad española del siglo XVI, con un discurso afin a la tradición escrita culta, instruida, como si situamos a Guamán Poma en una comunidad que atraviesa un violento período de recomposición social y lingüístico, donde la norma era el analfabetismo, la discriminación y el monolingüismo en lengua andina. Que, en ese contexto, un indígena, Guamán Poma, escriba en español, interferido o como se quiera, una carta al Rey es, por donde se mire, un hecho notable. Me he ocupado de detalles conexos a esta nota en Garatea (2017 y 2018).

${ }^{16}$ No fue Guamán Poma ajeno a las exigencias del estilo. En la supuesta carta de presentación que dirige el padre del autor al Rey, dando fe de la valía de la obra, se lee el siguiente juicio sobre el estilo: «... Y que el estilo es fázil y graue y sustancial y prouechoso a la santa fe católica y la dicha historia es muy uerdadera como conbiene al supgeto y personas de quien trata...» $(7 / 7)$. 
virtudes de su trabajo. Es un tránsito que le permite llevar a las letras españolas lo que existe en sonidos de varias lenguas indígenas. Lo dice al inicio de la Crónica:

PRÓLOGO AL LETOR CRISTIANO / que leyere deste dicho libro, biendo la ocación en las manos al escrito, para sacar en linpio estas dichas historias ube tanto trauajo por ser cin escrito ni letra alguna, cino más de quipos * y rrelaciones de muchas lenguaxes ajuntando con la lengua de la castellana y quichiua ynga, aymara, poquina colla, canche, cana, charca, chinchaysuyo, andesuyo, collasuyo, condesuyo, todos los bocablos de yndios, que pasé tanto trauajo por ser serbicio de Dios Nuestro Señor y de su Sacra Católica Magestad, rrey don Phelipe el terzero (11/11)

En Guamán Poma no hay señal de lamento ni espacio para enfatizar la oposición entre el mundo oral y el escrito ni para sacar consecuencias de la pérdida de memoria, como sucede en los fragmentos del Inca citados atrás. El cronista mira adelante y expresa las virtudes que trae consigo saber escribir y defiende su enseñanza. Para él, se trata de un medio que, a pesar de personificar muchas veces la intolerancia y el abuso que padece la población indígena, debe ser alentado entre sus paisanos. No promueve su rechazo. Por el contrario, subraya su utilidad y su función social y de gobierno. Lo afirma cuando, por ejemplo, menciona el buen gobierno, incluyendo, por cierto, en el mismo párrafo, a los traductores:

484[488] / BVEN GOBIERNO / PRICIDENTE I OIDORES de su Magestad y alcaldes de corte y fiscal, alguazil mayor deste rreyno / audiencia real* Que para el buen gobierno a de auer un letrado y después dos protetores que partan el salario y dos proquradores y $\mathrm{u}[\mathrm{n}]$ lengua y una persona que sepa la lengua y haga en borra[dor] memoriales para que entienda el letrado, protetores... (484/488)

El alegato es luego trasladado al mundo indígena. A criterio de Guamán Poma, todo indio principal debe saber escribir para ejercer adecuadamente el cargo. Pero no solo debe saber leer y escribir sino que también debe saber latín. Lo dice en las líneas siguientes en las que, al pasar, da cuenta de dos tipos textuales, la petición y el interrogatorio, ampliamente usados en el mundo colonial como parte de la diversidad textual que dio materia y sustancia al ejercicio del poder colonial en sus distintas facetas ${ }^{17}$. Dice el cronista:

17 En otro momento expondrá algunos otros tipos de textos habituales en el derecho y en la Iglesia, el pasaje que cito trae además una referencia al poder de la palabra escrita sobre la oral: [817/831] Que todas las justicias seglares, ygl[e]ciásticos destos rreynos rreciuan las peticiones y memoriales, enterrogatorios, abisado o carta que los yndios lo dieren y presentaren, aunque sea en lengua de yndio. Aunque sea un rreglón, al pie de ella lo rresponda y con 
771[785] / PRINCIPALES / Caciques principales sean desaminados la lengua de Castilla y general de quichiua y sea prouado y criado cin chicha y no aproeue uino en su bida ni juegue ningún juego. Y para ello se a de criarse cristiano ladino y, ci pudiere, sepa latín y leer, escriuir, contar y sepa ordenar peticiones y enterrogatorios para defensa de sus personas y de sus yndios y supgetos, bazallos, pobres de Jesucristo ${ }^{18}$.

Y quien no supiere leer y escribir, para Guamán Poma, no solo es «bárbaro animal» sino que, además, no debe ser cristiano, afirmación que muestra nuevamente que no se opone a muchos principios políticos, religiosos y culturales impuestos por la administración colonial; para él, no son ellos el problema; el problema está en la manera en que son aplicados y en los desarreglos y atropellos que realizan en nombre del Rey soldados, curas y administradores virreinales. Estas son las palabras del autor:

782 [796]: Que los dichos caciques principales y yndios, yndias, niños niñas en este rreyno todos sepan la lengua de Castilla, leer y escriuir como españoles, españolas. Y al quien no la supiere, le tengan por bárbaro animal, cauallo; no pueda ser cristiano ni cristiana ${ }^{19}$.

Aunque la política lingüística impulsó desde muy temprano la enseñanza de la lectura y de la escritura en la población amerindia, obviando muchas veces la falta de maestros, de personas capacitadas y sobre todo, aunque luego enmendó, el pésimo dominio de la lengua indígena, los resultados son muy heterogéneos y dependen de la época, del lugar y del entorno político y social ${ }^{20}$. Quienes recibieron el encargo de conducir la educación indígena fueron los miembros del clero, los que, por razones

la rrespuesta se las buelba para su derecho, justicia, aunque sea yndio alcalde. Jamás haga justicia de palabra, cino que sea de letra, para que le conste al dicho corregidor. Ci uiniere de palabra, no le oyga y pida escrito. Y ací su Magestad uerá y proueerá. Y no se las rronpa ni se la esconda y no concienta que busque letrado, cino rreciba bien hecha, mal hecha las dicha $[\ldots]$ las dichas $[s i c]$ peticiones. Desto rreciben muy mucho agrauio y ací jamás alcansan justicia ni lo tendrán. [818-832]

${ }_{18}$ En el mismo sentido pueden consultarse, entre otras, las páginas 758, 762, 766, 770, 784, 785, 796, 799, 803, 807, 838, 872, 906.

${ }^{19}$ Con un sentido más bien positivo se refiere Guamán Poma a las bondades de saber leer y escribir, vinculándolo con ser buen cristiano: «671 [685] IGLESIA Maestro de coro y de escuela de este reino Que los dichos maystros an de enseña[r] los muchachos, niños, niñas, mosos y las donzellas, que a los muchachos en la escuela y a las niñas y donzellas en sus casas. Se le tome lición y le enseñe a leer y [e]scriuir para que sean cristianas y que tengan ojo y ánima para el cielo».

${ }^{20}$ Resulta especialmente ilustrativa la recopilación documental de Konetzke incluida en la bibliografía porque da cuenta de las coincidencias y de las divergencias en lo referido a política lingüística colonial; por su parte, los ejemplos señalados por Cerrón Palomino (2010) y los trabajos de Durston (2007 y 2008) ofrecen una serie de éxitos y fracasos en la instrucción indígena. 
prácticas antes que pedagógicas, vieron en ello la oportunidad para dominar espiritualmente al indígena y obligarlo a abandonar sus creencias y un modo de vivir distinto del suyo, incapaces de comprenderlo y verlo como expresión de una cosmovisión y de una religiosidad diferente. No se hicieron esperar las denuncias contra frailes y misioneros por abusos de distinta calaña, desde robos hasta violencia sexual. Pronto el temor a ser denunciados los convirtió en enemigos de la alfabetización indígena. Era preferible conservar al indígena analfabeto que permitirle acceso a un conocimiento que podría ser empleado en su contra. Prefirieron incumplir la ley antes que exponerse a ser denunciados por sus alumnos ${ }^{21}$. Guamán Poma lo dice con todas sus letras:

590 [604] P [adres] Que los mismos padres enpide a que no sepa leer ni escriuir ni gusta que ayga maystro de escuela porque no sepan pleytos y hordenansas y serbicio de Dios nuestro señor y de su Magestad. Lo haze para que no lo aciente sus bellaquerías y maldades y rrobos. Y ancí hazen grandes daños y tray beynte hijos, rrescates. Todas las chinas [criada] lo ajunta yndias de mal biuir, putas; a las dichas buenas enseñan estas dichas putas de los padres. Con todo ello ay grandícimo escándolo.

Luego insiste:

714 [728] Mira, cristiano, esta mala rreprehención y mal exenplo de saserdote, cómo no quiere que ayga cristiano ni pulicía. Y ací no gusta que ayga escuela ni que sepa ler y escriuir, quiere que sean ynfieles ydúlatras ${ }^{22}$.

¡Qué mundo más contradictorio! Es este tipo de situaciones el que justifica las cautelas cuando se efectúan generalizaciones en el mundo colonial hispanoamericano, previsión que vale para ayer pero también para hoy. Pensó Guamán Poma que la alfabetización de niños era un recurso adecuado y eficaz contra la idolatría, el gran temor del creyente y el pretexto más usado para reprimir a la población indígena. La escritura estaba del lado de la fe y de una iglesia que pugnaba por consolidar su presencia en el territorio y en la conciencia del indígena. En ese marco se sitúa el fragmento siguiente, unas líneas que concluyen con la historia de un engaño y que, además del humor negro que destila la situación, realzan la importancia que tuvieron la lectura y la escritura en un sector de la población andina.

${ }^{21}$ Rivarola (2010) dio a conocer un expediente en el que los indios capitulan a su cura.

${ }^{22}$ Léase ahora este fragmento: «Cin buena sangre y cin letra, no se puede rregir ni gouernar la letra de Dios y leys destos rreynos ni será obedecido ni rrespetado. Estas dos cosas a de tener para el buen gobi[e]rno del seruicio de Dios y de su Magestad y buena justicia del mundo y deste rreyno» $(657 / 671)$. 
Que en este rreyno en los pueblos chicos o grandes ayga escuela y sepan leer, escriuir, cantar canto de órgano los dichos niños y niñas todos. Porque ací conbiene para el seruicio de Dios y de su Magestad y buena pulicía y cristiandad. [...] Y cin falta sepa leer, escriuir los niños, niñas en todo el mundo y más en este rreyno. Y ancí se perderá la ydúlatra y serimonia de los demonios. [...] Que un maestro estaua en Santiago de Queros, un yndio llamado Damián, yndio Changa, del pueblo de Santiago de Uayanay, el qual se auía consertado por un año de enseñar a los muchachos leer, escriuir, cantar por ochenta pesos y de comer. Porque le daua gusto al padre, se le pagaron y en todo el año no le enseñó a los muchachos de la dicha escuela ni sauía la dotrina. Todos los días estaua borracho, perdido y uellaqueando y ganando salario por el gusto del padre a costa de los yndios. $(676 / 686)$

\section{FINAL}

Decía al empezar que la historia del español americano es también la historia del español escrito. En estas páginas he ofrecido unas cuantas notas en torno a dos obras emblemáticas y singulares de la historiografía colonial. Las citas son parte de un universo que, debidamente delimitado, puede dar pie a distintas líneas de investigación y llevar al investigador al otro lado de la historia de la lengua, el espacio en el que la diglosia y la asimetría se convirtieron y refundieron en nuevos ideales de prestigio y en modelos de enseñanza idiomática que ahogaron y sometieron a las lenguas indígenas e impusieron a la lengua española en un nuevo contexto; con esos modelos trasmitieron valoraciones y juicios sobre la diversidad, la variación, y difundieron expresiones empleadas para juzgar el uso del español en la escritura o en la espontaneidad de la vida diaria. Tal vez es ese el camino que debemos seguir para ver cómo se instauraron modelos de corrección, tradiciones discursivas, una idea de lengua estándar en América y cómo esos modelos entran luego en pugna con la fuerza de la naciente variación americana y con los efectos que, en diferentes niveles, expresa la fuerza del contacto de lenguas. Aún tenemos mucho que recorrer si avistamos el camino que abre la escritura en América, su difusión, su adopción, los métodos y los modelos empleados en su enseñanza, por ejemplo, temas que necesitan más trabajo y nuevos documentos. Esa ruta permitirá recuperar la historia integral del español de América y nos pondrá ante los recodos en los que se fraguó la diversidad de modalidades de hablar español que ahora nos une y nos separa en Hispanoamérica. Tanto el Inca Garcilaso como Guamán Poma dan algunas luces sobre los pesos y contrapesos de esa historia pero todavía queda mucho por hacer. 


\section{BIBLIOGRAFÍA}

Adorno, Rolena (1989): Cronista y príncipe. La obra de Felipe Guamán Poma de Ayala, Lima: PUCP.

- (1991): Guamán Poma: Literatura de resistencia en el Perú colonial, México: Siglo XXI.

Bustos Tovar, Jesús (2000): «Texto, discurso e historia de la lengua», Revista de Investigación Lingüistica 3, 67-94.

CÁRDEnAS, José (1997): «Escribir es nunca acabar: una aproximación a la conciencia lingüística de Huamán Poma de Ayala», Lexis 21, 53-84.

- (2001): «Notas filológicas para la génesis de la Nueva crónica y buen gobierno». En F. Cantú (ed.), Guamán Poma y Blas Valera. Tradición andina e historia colonial, Roma: Pellicat, 21-48.

Cerrón Palomino, Rodolfo (2003): Castellano andino. Aspectos sociolingüísticos, pedagógicos y gramaticales, Lima: PUCP/Cooperación técnica alemana.

- (2010): «El contacto inicial quechua-castellano: la conquista del Perú con dos palabras», Lexis 34, 369-381.

- (2013): Tras las huellas del Inca Garcilaso. El lenguaje como hermenéutica en la comprensión del pasado, Boston: Centro de estudios literarios Antonio Cornejo Polar/RCLL.

DuRsTON, Alan (2003): «La escritura del quechua por indígenas en el siglo XVIII. Nuevas evidencias en el Archivo Arzobispal de Lima (estudio preliminar y edición de textos)», Revista Andina 37, 207-234.

- (2007): Pastoral Quechua: the history of Christian translation in colonial Peru, 15501650, California: University of Notre Dame Press.

- (2008): «Native-Language Literacy in Colonial Peru: The Question of Mundane Quechua Writing Revisited», Hispanic American Historical Review 88/1, 42-70.

Garatea Grau, Carlos (2005): «Textos, escritura y voz en la historia del español de América», Anuario de Letras XLII-XLIII, 365-376.

- (2010): Tras una lengua de papel. El español del Perú, Lima: PUCP.

- (2013): «El Inca Garcilaso, autoridad del español». En W. Oesterreicher y R. Schmidt-Riese (eds.), Universos semióticos, textualidad y legitimación de saberes en la América colonial, Frankfurt: De Gruyter, 77-98.

- (2015a): «La idea de lengua en los Comentarios reales del Inca Garcilaso de la Vega», Romanistisches Jahrbuch 65, 256-276.

- (2015b): «El inca Garcilaso en el Diccionario de Autoridades». En M. Guzmán y D. Sáez (eds.), Márgenes y centros en el siglo XVIII, Valencia: Tirant, 43-58.

- (2017): «Tres historias sobre el español del Perú: La blanca, la india y la mestiza», Lingüistica 33, 107-120.

- (2018): «Guamán Poma de Ayala: la historia de una variedad americana», en M. ${ }^{a}$ L. Arnal Purroy et al. (coords.), Actas del X Congreso Internacional de 
Historia de la Lengua Española (Zaragoza, 7-11 de septiembre de 2015), Zaragoza: Institución Fernando el Católico, vol. 1, 193-213.

- (2019): «El concepto de lengua materna y el monocentrismo hispánico», Cuadernos de la ALFAL 11(1), 120-129.

Garcilaso DE LA VeGA, Inca: ([1609]1991): Comentarios reales de los Incas, edic. C. Araníbar, Lima: FCE.

GODENZZI, Juan C. y Carlos GARATEA G. (2017): Literaturas orales y primeros textos coloniales, Vol. I, Lima: PUCP.

Guamán Poma de Ayala (1615/1980): Nueva corónica y buen gobierno, edición crítica de J. Murra y R. Adorno, México: Siglo XXI.

Koch, Peter y Wulf Oesterreicher (2007): Lengua hablada en la Romania: español, francés, italiano, Madrid: Gredos.

KonETZKe, Richard (1953): Colección de documentos para la historia de la formación social de Hispanoamérica (1493-1810), T. I, Madrid: CSIC.

- (1984): América latina II. La época colonial, México: Siglo XXI.

MANNHEIM, Bruce (1989): «La memoria y el olvido en la política lingüística colonial», Lexis XIII, 13-46.

NARbona, Antonio (2008): «La problemática descripción del español colonial». En E. Stark et al. (eds.), Romanische Syntax im Wandel, Tübingen: Narr, 549-565.

- (2015): Sintaxis del español coloquial, Sevilla: Universidad de Sevilla.

OESTERREICHER, Wulf (1997): «Cajamarca 1532 - diálogo y violencia. Los cronistas y la elaboración de una historia andina», Lexis 21, 211-271.

QUisPe, Rocío (2006): La fe andina en la escritura: resistencia e identidad en la obra de Guamán Poma de Ayala, Lima: UNMSM.

Rivarola, José Luis (1990): La formación lingüistica de Hispanoamérica, Lima: PUCP.

- (2000): Español andino. Textos de bilingues de los siglos XVI y XVII, Madrid: Vervuert.

- (2001): «La lengua materna. Conciencia lingüística y conciencia retórica en el Inca Garcilaso», El español de América en su historia, Valladolid: Universidad de Valladolid, 159-179.

- (2002): Comentarios reales de los incas. Estudio, Madrid: ACI.

- (2003): «Sobre el estilo del inca Garcilaso». En J. L. Girón Alconchel et al. (eds.), Estudios ofrecidos al profesor José Jesús Bustos Tovar, Madrid: Ed. Complutense, 1301-1310.

- (2009): Documentos linguísticos del Perú. Siglos XVI y XVII, Madrid: CSIC.

- (2010): «Los indios capitulan a su cura». En W. Oesterreicher y R. SchmidtRiese (eds.), Esplendores y miserias de la evangelización, Berlin: De Gruyter, 213246.

Rodríguez Garrido, José Antonio (1993): «Las citas de los cronistas españoles como recurso argumentativo en la segunda parte de los comentarios reales», Lexis 27, 93-114.

Rosenblat, Ángel (1967/2017): Estudios sobre el español de América 2, Sevilla: Athenaica, 4-14.

Solano, Francisco (comp.) (1992): Documentos sobre política lingüistica en Hispanoamérica (1492-1800), Madrid: CSIC.

VALdÉs, Juan de ([1535]1989): Diálogo de la lengua, México: Porrúa. 